Freedom and Education 


\section{University of Pennsylvania Schoolmen's Week}

Schoolmen's Week Meeting October 9-12, 1963 


\title{
Freedom and Education
}

\author{
Fifty-first \\ Schoolmen's Week Proceedings
}

Edited by

HELEN HUUS

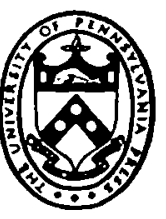

Philadelphia

UNIVERSITY OF PENNSYLVANIA PRESS 
(C) 1965 by the Trustees of the University of Pennsylvania

Published in Great Britain, India, and Pakistan

by the Oxford University Press

London, Bombay, and Karachi

Library of Congress Catalogue Card Number: 61-311

7455

Printed in the United States of America 